Article

\title{
Intrapreneurial Self-Capital and Connectedness to Nature within Organizations
}

\author{
Mirko Duradoni ${ }^{1}\left[\mathbb{D}\right.$ and Annamaria Di Fabio ${ }^{2, *}$ \\ 1 Department of Information Engineering, University of Florence, via S. Marta 3, 50139 Florence, Italy \\ 2 Department of Education, Languages, Intercultures, Literatures and Psychology (Psychology Section), \\ University of Florence, 50135 Florence, Italy \\ * Correspondence: adifabio@psico.unifi.it; Tel.: +39(0)55-2055850; Fax: +39(0)55-2756134
}

Received: 21 May 2019; Accepted: 4 July 2019; Published: 5 July 2019

\begin{abstract}
Research exists regarding personality traits in relation to connectedness with nature. However, it is not possible to increase personality through training. As an alternative, intrapreneurial self-capital (ISC) could be a promising core of resources for enhancing the sustainable development of behaviors and practices. Using a sample of 198 workers, this study exploratively analyzed the relationship between the extraversion personality trait, ISC, and connectedness to nature. A mediation model was employed to assess the effects of extraversion on connectedness to nature (outcome variable) through ISC (conceived as an intervening mediator variable). The mediation analysis highlighted that ISC potentially promotes workers' connectedness to nature within organizations. Thus, implementing dedicated interventions to increase ISC could encourage sustainable development by enhancing workers' levels of connectedness to nature.
\end{abstract}

Keywords: intrapreneurial self-capital; connectedness to nature; psychology of sustainability and sustainable development; sustainability; extraversion

\section{Introduction}

The importance of the psychological aspects related to sustainable development has grown in recent years to such an extent that the psychology of sustainability and sustainable development has given birth to a thriving and trans-disciplinary area of research [1-3]. Indeed, in order to meet the Sustainable Development Goals, which were introduced by the United Nations (UN) [4], scholars were asked to concretely specify how to manage and realize the processes related to sustainability and sustainable development. In this sense, adopting a psychological perspective could foster the behaviors and practices of sustainable development, as well as improve people's quality of life $[1-3,5]$. Within the psychology of sustainability and sustainable development, particular attention has been given to the natural environment thematic, by investigating the connectedness to the nature construct [6,7]. Connectedness to nature refers to how people identify with the natural environment and the relationships they form with nature [7]. The definition of connectedness to nature encompasses two main aspects: (a) the individuals' cognitive representation of self [8], and (b) their affective and experiential connection with nature [6]. Scientific literature has shown that exposure to nature positively affects people's physical and psychological well-being $[9,10]$. Additionally, a higher level of connectedness to nature can promote pro-environment behaviors [7,8,11-14], thereby encouraging and facilitating sustainable development processes.

Indeed, according to the self-expansion model, as connectedness to nature increases (i.e., people include nature more in their representation of self), so does ecological behaviors [6]. The potential connectedness to the nature construct in shaping pro-environmental and sustainable practices led to the development of a line of research to investigate what factors it could affect. A great number of 
studies have explored the connectedness of nature with personality traits [15-19]. From these studies emerged evidence that the extraversion personality trait, which is defined as people's tendency to sociability, talkativeness, assertiveness, and excitability [20], can be related to a connectedness with nature. Extraversion also appeared to positively contribute to environmental awareness [21] and environmental behaviors [22,23].

The positive sustainable development framework is centered on promoting human resources suitable for facing the continuous challenges of our century and supporting the processes of personal growth and flexible change [24-26]. The research in this area has recently intensified its efforts towards personality traits, which are traditionally considered stable [27], but it has also begun to consider factors different from personality. Therefore, other constructs have been taken into account within the psychology of sustainability and sustainable development; among these, intrapreneurial self-capital (ISC) has received increasing consideration [28-31]. The ISC construct has been defined by Di Fabio [28] as a higher-order construct (i.e., a core of individual resources) that includes the following first-order constructs: core self-evaluation, hardiness, creative self-efficacy, resilience, goal mastery, decisiveness, and vigilance. In general, intrapreneurial self-capital encompasses the positive self-evaluation of one's own ability to be committed, to identify significant objectives, to feel in control of life events, to solve problems creatively, to change constraints into resources, to develop one's own skills, to apply decision-making skills to every life situation, and to make accurate and adaptive decisions [28,32]. A correlation between ISC and connectedness to nature could be plausible on a theoretical basis, since both constructs appeared to contribute, albeit differently, to sustainable development processes [19,29] and people's well-being [9,10,32-34]. Such a relationship could also be justified on the basis of the self-expansion model. People who seek to expand the self are driven by the desire to increase resources, perspectives, and identities in order to achieve their goals and objectives (i.e., self-expansion motivation) [35]. ISC could facilitate the self-expansion process by offering a core of resources that plausibly favor the inclusion of nature as a part of people's selves. As a result, those individuals who identify more with nature, and thus successfully integrate nature in their selves, could have acquired resources like ISC, and this may have helped them to structure their "expanded" self. Finally, recent studies have highlighted that ISC is correlated with extraversion [33,34], suggesting that ISC and connectedness to nature could be affected by the same personality trait. In general, extraversion could be a favorable psychological feature that might help to reach connectedness to nature [15-19], which can be increased further by having acquired resources like ISC. Thus, in this study, the authors tested whether ISC could mediate the relationship between extraversion and connectedness to nature.

\section{Materials and Methods}

\subsection{Objective of the Study}

The objective of the present study was to verify whether intrapreneurial self-capital would mediate the relationship between personality traits and connectedness to nature among workers [15-19].

ISC already appeared to be able to mediate the extraversion effect on other constructs (e.g., innovative behavior) [29] using a measure of personality based on the five-factor model. The relationship between personality, ISC, and connectedness to nature has been explored in this study with a different personality model (i.e., Eysenck Model), however this still encompasses extraversion among the traits, with the aim to expand the evidence regarding these variables.

ISC can dampen risks and build people's strengths to adaptively face the 21st-century's challenging environment. As defined within the primary prevention framework [25,36-38], ISC can be conceived as a core of resources that can modulate the effects of personality traits. ISC was selected as a possible mediator between personality and connectedness to nature because in previous empirical works it demonstrated that it could add a significant incremental portion of variance in the relationship between personality and expected positive outcomes [33,34]. Moreover, on the basis of the self-expansion model, ISC could be considered a possible core of resources useful for facilitating the inclusion of 
nature in people's self-representation. Connectedness to nature was selected as the dependent variable in terms of a positive outcome, since it was considered a proxy for making inferences about important environmentally protective and responsible behaviors [19].

Researchers formulated the following hypotheses:

Hypothesis 1 (H1). Extraversion is positively correlated with both intrapreneurial self-capital and connectedness to nature.

Hypothesis 2 (H2). Intrapreneurial self-capital and connectedness to nature are positively correlated.

Hypothesis 3 (H3). Intrapreneurial self-capital mediates the effect of extraversion on individuals' connectedness to nature.

\subsection{Participants}

The study participants were 247 Italian workers (52.2\% females) from different public and private organizations, with an average age of 41.86 (standard deviation $=11.44$ ).

\subsection{Measures}

\subsubsection{Connectedness to Nature Scale (CNS) - Italian Version}

The Italian version [39] of the Connectedness to Nature Scale (CNS) [6] consists of 14 items measured via a five-point Likert-type scale (ranging from $1=$ Strongly agree to $5=$ Strongly disagree) that investigates the individuals' trait levels of feeling emotionally connected to the natural world. Examples of items are: "I often feel a sense of oneness with the natural world around me", "I think of the natural world as a community to which I belong", and "I have a deep understanding of how my actions affect the natural world". The reliability coefficient of the CNS total score is 0.91 for the Italian version and 0.84 for the original version. Moreover, the dimensionality indices of the Italian version appeared satisfactory $\left(\chi^{2} / \mathrm{df}=2.16\right.$; Tucker Lewis index or non-normed fit index $(\mathrm{NNFI})=0.92$; comparative fit index $(\mathrm{CFI})=0.94$; root mean square error of approximation $($ RMSEA $)=0.07)$.

\subsubsection{Eysenck Personality Questionnaire-Revised Short Form (EPQ-RS)—Italian Version}

The Italian version [40] of the Eysenck Personality Questionnaire (EPQ) [41] consists of 48 dichotomic items (yes/no) that evaluate personality traits. There are 12 items for each of the four personality dimensions considered: (a) extraversion, which concerns participants' sociability and vivacity; (b) neuroticism, which describes the participants' emotions on a continuum that ranges from emotional stability to emotional instability; (c) psychoticism, which is defined as an underlying predisposition of personality, present in varying degrees in all people, to develop anomalies of a psychiatric nature; and (d) lie, which measures dissimulation. The Cronbach's alpha coefficients for the Italian version were 0.78 for the extraversion dimension, 0.85 for the neuroticism dimension, 0.67 for the psychoticism dimension, and 0.75 for the lie dimension. Finally, EPQ showed acceptable dimensionality indices $\left(\chi_{(406)}^{2}=860.87\right.$; Tucker Lewis index or non-normed fit index $(\mathrm{NNFI})=0.93$; comparative fit index $(\mathrm{CFI})=0.94$; standardized root mean square residual $(\mathrm{SRMR})=0.07)$.

\subsubsection{Intrapreneurial Self-Capital Scale (ISCS)—Italian Version}

The Intrapreneurial Self-Capital Scale (ISCS) [28] uses 28 items measured on a five-point Likert-type scale to assess the intrapreneurial self-capital construct, which encompasses self-evaluation, hardiness, creative self-efficacy, resilience, goal mastery, decisiveness, and vigilance aspects. The reported Cronbach's alpha coefficient for the ISCS total score is 0.86 for the Italian version. The psychometric properties of the scale were reported by Di Fabio [28]. The ISC scale showed appropriate and adequate 
dimensionality indices $\left(\chi^{2} / \mathrm{df}=1.43\right.$; Tucker Lewis index or non-normed fit index $(\mathrm{NNFI})=0.90$; comparative fit index $(\mathrm{CFI})=0.90$; root mean square error of approximation $(\mathrm{RMSEA})=0.05$; standardized root mean square residual $(S R M R)=0.04)$.

\subsection{Procedure}

Trained psychologists administered the questionnaires to the workers in group sessions, in accordance with Italian law requirements regarding privacy and informed consent (Law Decree DL-101/2018) and EU regulations (2016/699) and in a counterbalanced order. Participants could withdraw from the data collection session at any time.

\subsection{Data Analysis}

The researchers first verified the preconditions necessary for mediation analysis. They assessed the variables' normality (asymmetry and kurtosis values), homoscedasticity, and linearity. For all the variables suitable for the mediation analysis, the gender-related differences underwent examination by means of the Student t-test and Cohen's d coefficient. Subsequently, the researchers carried on the regression procedures recommended by Hayes [42] for the assessment of mediation using PROCESS version 3.2 [43]. Mediation processes were framed in terms of intermediate variables (i.e., mediators, $\mathrm{M})$ between an independent variable $(\mathrm{X})$ and a dependent variable $(\mathrm{Y})$. For simple mediation models (i.e., theoretical model 4 ) three variables are required (i.e., $M, X, Y$ ).

According to Hayes [42], $X$ could affect $Y$ only in two ways in a simple mediation model (i.e., directly and indirectly through the mediator). Complete or full mediation occurs when variable $X$ no longer affects $\mathrm{Y}$ after $\mathrm{M}$ has been controlled, while partial mediation refers to those cases in which the path from $X$ to $Y$ is reduced in absolute size but is still statistically significant when the mediator is introduced. The researchers proceeded to estimate the effect sizes of the mediator (i.e., how much of the independent variable's effect possibly attributes to the mediator).

\section{Results}

\subsection{Descriptive Statistics}

Table 1 reports the descriptive statistics for the workers sample. Mean and standard deviation are presented for all the variables collected.

Table 1. Descriptive Statistics.

\begin{tabular}{ccc}
\hline Scale & Variable & Mean (s.d.) \\
\hline \multirow{2}{*}{ EPQ } & Extraversion & $8.13(3.28)$ \\
\cline { 2 - 3 } & Psychoticism & $2.96(2.15)$ \\
\cline { 2 - 3 } & Neuroticism & $4.65(3.06)$ \\
\hline \multirow{2}{*}{ CNS } & Total Score & $48.04(8.86)$ \\
\hline ISCS & Total Score & $102.04(12.10)$ \\
\hline
\end{tabular}

Note. s.d. = standard deviation; EPQ = Eysenck Personality Questionnaire; CNS = Connectedness to Nature Scale; ISCS = Intrapreneurial Self-Capital Scale.

\subsection{Mediation Assumptions and Gender Differences}

The relationships between personality traits, connectedness to nature, and intrapreneurial self-capital were assessed by means of Pearson's r coefficient (i.e., correlation).

As shown in Table 2, intrapreneurial self-capital correlated with CNS, extraversion, and neuroticism. However, CNS showed only a positive linear relationship with extraversion (among personality traits) and ISC. Since neuroticism and psychoticism did not individually show a positive linear relationship with both ISC and CNS, these variables could not be used in mediation analysis. Instead, extraversion, 
entertaining a significant linear relationship with both ISC and CNS, received inclusion in the mediation analysis. Gender effects on extraversion, ISC, and CNS were explored by researchers before proceeding with mediation analysis.

Table 2. Full correlation matrix between personality traits, connectedness to nature, and intrapreneurial self-capital.

\begin{tabular}{|c|c|c|c|c|c|}
\hline Variable & Extraversion & Psychoticism & Neuroticism & CNS & ISC \\
\hline Extraversion & 1 & $-0.17^{* *}$ & $-0.26^{* * *}$ & $0.24^{* * *}$ & $0.38^{* * *}$ \\
\hline Psychoticism & $-0.17^{* *}$ & 1 & 0.03 & -0.02 & -0.08 \\
\hline Neuroticism & $-0.26^{* * *}$ & 0.03 & 1 & -0.09 & $-0.30^{* * *}$ \\
\hline CNS & $0.24^{* * *}$ & 0.02 & -0.09 & 1 & $0.40^{* *}$ \\
\hline ISC & $0.38^{* * *}$ & -0.08 & $-0.30^{* * *}$ & $0.40^{* *}$ & 1 \\
\hline
\end{tabular}

As seen in Table 3, extraversion $\left(t_{(243)}=0.08 ; p=0.94\right)$, CNS $\left(t_{(243)}=-1.37 ; p=0.17\right)$, and ISC $\left(t_{(243)}=0.60 ; p=0.55\right)$ were influenced in a small and non-significant way by gender. Besides this, none of the variables involved in the Student t-tests achieved a small gender-related effect size [44]. Since gender did not affect any the three variables selected for mediation analysis in a statistically significant way, the researchers excluded gender from the subsequent mediation analysis.

Table 3. Gender differences among the variables selected for mediation analysis.

\begin{tabular}{|c|c|c|c|c|c|}
\hline \multirow{2}{*}{ Variable } & \multicolumn{2}{|c|}{ Women } & \multicolumn{2}{|c|}{ Men } & \multirow{2}{*}{$\begin{array}{c}\text { Gender Differences } \\
\text { Cohen's d }\end{array}$} \\
\hline & $M$ & s.d. & $M$ & s.d. & \\
\hline Extraversion & 8.09 & 3.30 & 8.13 & 3.29 & 0.01 \\
\hline ISC & 101.49 & 12.18 & 102.43 & 12.00 & 0.08 \\
\hline CNS & 48.78 & 9.14 & 47.22 & 8.60 & 0.17 \\
\hline
\end{tabular}

Note. $M=$ mean; s.d. = standard deviation.

\subsection{Mediation Analysis}

Given the previous results, the researchers carried on a mediation analysis using extraversion as the independent variable and intrapreneurial self-capital as the mediator, while connectedness to nature was considered the dependent variable. The effect of extraversion on the mediator (ISC) was accounted by path $a$, while path $b$ signaled how much the mediator affected the outcome variable (i.e., CNS). Finally, path $\mathrm{c}^{\prime}$ and path $\mathrm{c}$ refer to the effect of the independent variable on the dependent variable when the mediator was, respectively, accounted or not. Figure 1 illustrates the relationship between extraversion and connectedness to nature, with intrapreneurial self-capital as a mediator. Table 4 displays the statistics related to all the paths accounted in simple mediation. 


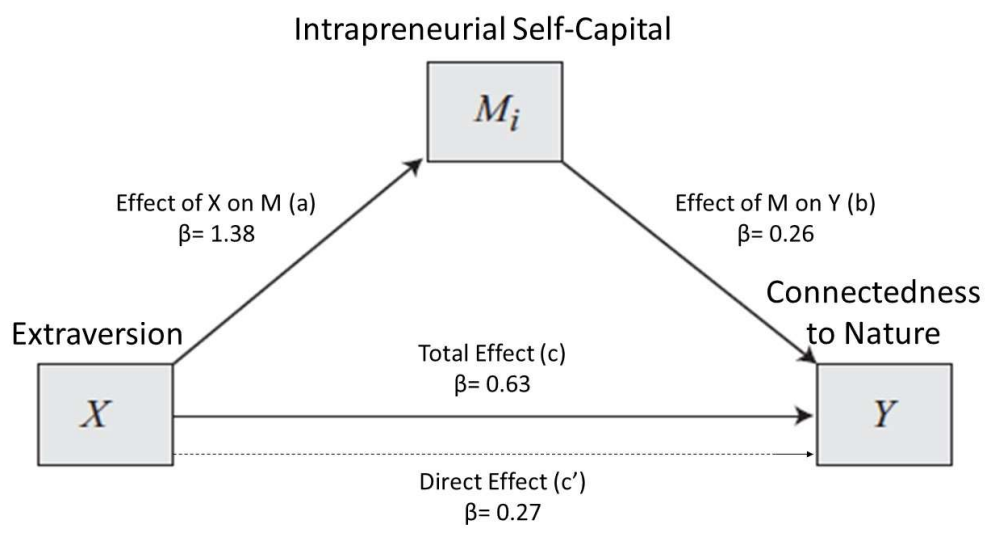

Figure 1. Relationship between extraversion and connectedness to nature, with intrapreneurial self-capital as a mediator $\left(\mathrm{k}^{2}\right.$ mediator effect size $=0.14$. $)$.

Table 4. Mediation analysis statistics.

\begin{tabular}{ccccc}
\hline & $\mathrm{F}$ & $\mathrm{df}$ & $p$ & $\mathrm{R}^{2}$ \\
\hline X predicts $\mathrm{M}$ & 40.10 & 1,245 & 0.001 & 0.14 \\
\hline X and M predict $\mathrm{Y}$ & 24.24 & 2,244 & 0.001 & 0.17 \\
\hline X predicts $\mathrm{Y}$ & 14.26 & 1,245 & 0.001 & 0.06 \\
\hline & Student $\mathrm{t}$ & $\mathrm{df}$ & $p$ & $\beta$ \\
\hline Path a & 6.33 & 245 & 0.001 & 1.38 \\
\hline Path b & 5.69 & 244 & 0.001 & 0.26 \\
\hline Path c' & 1.58 & 244 & 0.11 & 0.27 \\
\hline Path c & 3.78 & 245 & 0.001 & 0.63 \\
\hline
\end{tabular}

In line with our hypothesis, extraversion exhibited a significant direct positive influence on connectedness to nature (path c) and affected it indirectly through intrapreneurial self-capital. Instead, the direct effect (path $c^{\prime}$ ) did not appear statistically significant (i.e., the extraversion effect on connectedness to nature was no longer significant when ISC was considered as mediator). Highly extraverted individuals reported a higher intrapreneurial self-capital (path a), and participants who had high scores in intrapreneurial self-capital appeared to be more connected with nature (path $b$ ). Table 5 presents the model effects indices.

Table 5. Model's effect indices.

\begin{tabular}{cccccc}
\hline Total Effect & Direct Effect & Indirect Effect & $\begin{array}{c}\text { Par. } \\
\text { Standardized } \\
\text { Indirect Effect }\end{array}$ & $\begin{array}{c}\text { Tot. } \\
\text { Standardized } \\
\text { Indirect Effect }\end{array}$ & $\mathbf{k}^{2}$ \\
\hline 0.63 & 0.27 & 0.36 & 0.04 & 0.14 & 0.14 \\
\hline
\end{tabular}

Table 5 shows that $14 \%$ of the variance in the connectedness to nature was explained by the mediator (i.e., intrapreneurial self-capital).

\section{Discussion}

The authors presented a mediation model that extended previous research by examining people's connectedness to nature and assessing the role of intrapreneurial self-capital as a mediator of extraversion among adult workers. 
First, researchers replicated and confirmed the literature results concerning the relationship (i.e., correlation) between extraversion and intrapreneurial self-capital, obtaining similar Pearson's $r$ coefficient values $[33,34](\mathrm{H} 1)$. The relationship between extraversion and connectedness to nature was also confirmed. In this case, the correlation coefficient resulted in higher values but was still in agreement with the previous literature [15-19] (H1). This study also tested the relationship between intrapreneurial self-capital and connectedness to nature, which had not yet received empirical exploration. The results highlighted a positive linear relationship between ISC and connectedness to nature (H2). Gender did not affect ISC levels in the sample. Thus, our results appeared in line with the recent evidence regarding ISC gender invariance [19].

Given the existence of such relationships, the researchers performed a mediation analysis. In line with Hypothesis 3, intrapreneurial self-capital fully mediated extraversion's effect on workers' connectedness to nature. Following the $\mathrm{k}^{2}$ interpretation of Preacher and Kelley [45], researchers obtained a medium mediator effect size for the proposed model. Interestingly, intrapreneurial self-capital appeared to be able to affect the relationship between extraversion and connectedness to nature using a personality reference model, $[46,47]$ which conceives personality as a psychological feature grounded in an individuals' genetics, and thus very unlikely change $[48,49]$.

Additionally, the evidence that the direct effect in the mediation model (i.e., when consideration was given to the mediator) became statistically insignificant suggested how intrapreneurial self-capital can be a key factor in promoting connectedness to nature. Indeed, extraversion no longer affects connectedness to nature when ISC has been accounted for. The indirect effect of extraversion can be understood with consideration to the tendency of highly extraverted individuals to act with the intention of increasing their own resources (from $X$ to $M$ ) [50]. In this sense, people with a high level of ISC, which is a core of individual resources [28], could make use of those strengths to enhance their connectedness to nature (from M to Y). For instance, they could adaptively make decisions related to the environment (vigilance and decisiveness aspects) and perceive themselves as more self-efficient (core self-evaluation aspect) in dealing with pro-environment behaviors, thus enhancing their likelihood to succeed. In line with the self-expansion model [6,35], the individuals who successfully included nature in their own self reported higher levels of ISC. This result may suggest that ISC resources could facilitate the achievement of a higher and deeper connectedness to nature.

In contrast to personality traits, intrapreneurial self-capital can be increased through specific training [51,52]. For this reason, ISC appears particularly suitable for primary prevention interventions [25,36-38]. Increasing workers' ISC resources could also contribute to sustainability efforts within organizations, by empowering individuals' capability to deal with issues and challenges of sustainability development (e.g., by making their connection with the natural environment deeper) as well as enhance their well-being $[9,10,32-34,53,54]$.

Our results are promising for offering policymakers a new viable perspective on how to deal with sustainability and sustainable development issues. We are at the fork in the road, we could continue to act only in a framework of emergency interventions (i.e., tertiary prevention) or we also could be interested in enhancing people's preventive resources in parallel. If future studies confirm these results, ISC could be a promising resource in this perspective. Also, educators could plausibly exploit our work in terms of current educational interventions [55]. They could benefit from activities in which preventive resources, like ISC, can be developed to support sustainable development processes. Following this perspective, it might be possible in the future to reduce the need for emergency interventions (i.e., tertiary prevention) and thus create the conditions for undesirable behaviors to occur less.

Nevertheless, several limitations of this study need discussion. First, the study's results cannot be considered conclusive for all Italian workers in any line of work, but only the workers from the specific context in the Tuscan region. Thus, more efforts should be made to expand the research regarding the mediation effect of ISC on connectedness to nature by recruiting different types of workers from 
different geographical areas in Italy. Foreign countries should be included in testing such a model in the future as well, since the ISC scale is becoming available in multiple languages [56].

In addition, other constructs should receive consideration for integration to improve the model presented. For instance, sustainable leadership [57] should reasonably be examined in the future in regard to its relationship with both intrapreneurial self-capital and connectedness to nature. This model could also be studied and integrated within the psychology of harmony as harmonization's framework [58], as well as expanded through the consideration of the peculiar dynamics within virtual environments [59-61], which can enhance or hinder sustainable development. Nevertheless, this research project falls within exploratory and correlational studies (i.e., causal relationships are not involved). Thus, future research should assess if causal relationships exist between extraversion, ISC, and connectedness to nature.

Despite the abovementioned limitations, this study suggests that intrapreneurial self-capital could encourage sustainable development within organizations [1,62], potentially enhancing workers' connectedness to nature. Since modern societal organizations are called to play an important role in achieving the UN's Sustainable Development Goals [4], and in facing new challenging work related dynamics, such as coopetition [63], further attention should be given to those psychological features, such as ISC, that are able to ease the processes associated with sustainable development [3].

Author Contributions: Conceptualization, M.D. and A.D.F.; Data curation, M.D. and A.D.F.; Investigation, M.D. and A.D.F.; Methodology, M.D. and A.D.F.; Writing-original draft, M.D. and A.D.F.; Writing-review \& editing, M.D. and A.D.F.

Funding: This research received no external funding.

Conflicts of Interest: The authors declare no conflict of interest.

\section{References}

1. Di Fabio, A. Positive Healthy Organizations: Promoting Well-Being, Meaningfulness, and Sustainability in Organizations. Front. Psychol. 2017, 8, 1938. [CrossRef] [PubMed]

2. Di Fabio, A. The Psychology of Sustainability and Sustainable Development for Well-Being in Organizations. Front. Psychol. 2017, 8, 1534. [CrossRef] [PubMed]

3. Di Fabio, A.; Rosen, M.A. Opening the Black Box of Psychological Processes in the Science of Sustainable Development: A New Frontier. Eur. J. Sustain. Dev. Res. 2018, 2, 47. [CrossRef]

4. United Nations about the Sustainable Development Goals. 2018. Available online: https://www.un.org/ sustainabledevelopment/sustainable-development-goals/ (accessed on 20 May 2019).

5. Ariza-Montes, A.; Giorgi, G.; Hernández-Perlines, F.; Fiz-Perez, J. Decent Work as a Necessary Condition for Sustainable Well-Being. A Tale of Pi(i)gs and Farmers. Sustainability 2019, 11, 1051. [CrossRef]

6. Mayer, F.S.; Frantz, C.M. The connectedness to nature scale: A measure of individuals' feeling in community with nature. J. Environ. Psychol. 2004, 24, 503-515. [CrossRef]

7. Restall, B.; Conrad, E. A literature review of connectedness to nature and its potential for environmental management. J. Environ. Manag. 2015, 159, 264-278. [CrossRef]

8. Schultz, P.W. Inclusion with Nature: The Psychology of Human-Nature Relations. In Psychology of Sustainable Development; Schmuck, P., Schultz, W.P., Eds.; Springer: Boston, MA, USA, 2002; pp. 61-78, ISBN 978-1-4615-0995-0.

9. Tauber, P. An Exploration of the Relationships among Connectedness to Nature, Quality of Life, and Mental Health. Master's Thesis, Utah State University, Logan, UT, USA, 2012.

10. Kamitsis, I.; Francis, A.J.P. Spirituality mediates the relationship between engagement with nature and psychological wellbeing. J. Environ. Psychol. 2013, 36, 136-143. [CrossRef]

11. Perkins, H.E. Measuring love and care for nature. J. Environ. Psychol. 2010, 30, 455-463. [CrossRef]

12. Bragg, E.A. Towards ecological self: Deep ecology meets constructionist self-theory. J. Environ. Psychol. 1996, 16, 93-108. [CrossRef]

13. Kals, E.; Schumacher, D.; Montada, L. Emotional Affinity toward Nature as a Motivational Basis to Protect Nature. Environ. Behav. 1999, 31, 178-202. [CrossRef] 
14. Dutcher, D.D.; Finley, J.C.; Luloff, A.E.; Johnson, J.B. Connectivity With Nature as a Measure of Environmental Values. Environ. Behav. 2007, 39, 474-493. [CrossRef]

15. Di Fabio, A.; Bucci, O. Green Positive Guidance and Green Positive Life Counseling for Decent Work and Decent Lives: Some Empirical Results. Front. Psychol. 2016, 7, 261. [CrossRef] [PubMed]

16. Di Fabio, A.; Kenny, M.E. Connectedness to nature, personality traits and empathy from a sustainability perspective. Curr. Psychol. 2018, 1-12. [CrossRef]

17. Tam, K.-P. Concepts and measures related to connection to nature: Similarities and differences. J. Environ. Psychol. 2013, 34, 64-78. [CrossRef]

18. Zhang, J.W.; Howell, R.T.; Iyer, R. Engagement with natural beauty moderates the positive relation between connectedness with nature and psychological well-being. J. Environ. Psychol. 2014, 38, 55-63. [CrossRef]

19. Di Fabio, A.; Rosen, M.A. Accounting for Individual Differences in Connectedness to Nature: Personality and Gender Differences. Sustainability 2019, 11, 1693. [CrossRef]

20. Eysenck, H.J.; Eysenck, S.B. On the unitary nature of extraversion. Acta Psychol. Amst. 1967, 26, 383-390. [CrossRef]

21. Liem, G.A.D.; Martin, A.J. Young people's responses to environmental issues: Exploring the roles of adaptability and personality. Personal. Individ. Differ. 2015, 79, 91-97. [CrossRef]

22. Fraj, E.; Martinez, E. Influence of personality on ecological consumer behaviour. J. Consum. Behav. 2006, 5, 167-181. [CrossRef]

23. Markowitz, E.M.; Goldberg, L.R.; Ashton, M.C.; Lee, K. Profiling the "Pro-Environmental Individual": A Personality Perspective. J. Pers. 2012, 80, 81-111. [CrossRef] [PubMed]

24. Blustein, D.L.; Kenny, M.E.; Di Fabio, A.; Guichard, J. Expanding the Impact of the Psychology of Working: Engaging Psychology in the Struggle for Decent Work and Human Rights. J. Career Assess. 2018, 27, 3-28. [CrossRef]

25. Di Fabio, A.; Kenny, M.E. From Decent Work to Decent Lives: Positive Self and Relational Management (PS\&RM) in the Twenty-First Century. Front. Psychol. 2016, 7, 361. [CrossRef] [PubMed]

26. Fabio, A.D.; Bernaud, J.-L.; Loarer, E. Emotional Intelligence or Personality in Resistance to Change? Empirical Results in an Italian Health Care Context. J. Employ. Couns. 2014, 51, 146-157. [CrossRef]

27. Costa, P.T.; McCrae, R.R. Four ways five factors are basic. Personal. Individ. Differ. 1992, 13, $653-665$. [CrossRef]

28. Di Fabio, A. Intrapreneurial Self-Capital: A New Construct for the 21st Century. J. Employ. Couns. 2014, 51, 98-111. [CrossRef]

29. Duradoni, M.; Di Fabio, A. Intrapreneurial Self-Capital and Sustainable Innovative Behavior within Organizations. Sustainability 2019, 11, 322. [CrossRef]

30. Di Fabio, A.; Duradoni, M. Intrapreneurial Self-Capital: A Primary Preventive Resource for Twenty-First Century Entrepreneurial Contexts. Front. Psychol. 2019, 10, 1060. [CrossRef]

31. Di Fabio, A.; Saklofske, D.H. The Contributions of Personality Traits and Emotional Intelligence to Intrapreneurial Self-Capital: Key Resources for Sustainability and Sustainable Development. Sustainability 2019, 11, 1240. [CrossRef]

32. Di Fabio, A.; Gori, A. Neuroticism and flourishing in white collar workers: From self-esteem to intrapreneurial self-capital for adaptive outcomes. In Neuroticism: Characteristics, Impact on Job Performance and Health Outcomes; Psychology of Emotions, Motivations and Actions; Nova Science Publishers: Hauppauge, NY, USA, 2016; pp. 129-146, ISBN 978-1-63485-323-1.

33. Di Fabio, A.; Palazzeschi, L.; Bucci, O. In an Unpredictable and Changing Environment: Intrapreneurial Self-Capital as a Key Resource for Life Satisfaction and Flourishing. Front. Psychol. 2017, 8. [CrossRef]

34. Di Fabio, A.; Kenny, M.E. Intrapreneurial Self-Capital: A Key Resource for Promoting Well-Being in a Shifting Work Landscape. Sustainability 2018, 10, 3035. [CrossRef]

35. Aron, A.; Aron, E.N.; Norman, C. Self-expansion Model of Motivation and Cognition in Close Relationships and beyond. In Self and Social Identity; Perspectives on Social Psychology; Blackwell Publishing: Malden, MA, USA, 2004; pp. 99-123, ISBN 978-1-4051-1069-3.

36. Hage, S.M.; Romano, J.L.; Conyne, R.K.; Kenny, M.; Matthews, C.; Schwartz, J.P.; Waldo, M. Best Practice Guidelines on Prevention Practice, Research, Training, and Social Advocacy for Psychologists. Couns. Psychol. 2007, 35, 493-566. [CrossRef] 
37. Kenny, M.E.; Hage, S.M. The Next Frontier: Prevention as an Instrument of Social Justice. J. Prim. Prev. 2009, 30, 1-10. [CrossRef] [PubMed]

38. Di Fabio, A.; Kenny, M.E. Promoting Well-Being: The Contribution of Emotional Intelligence. Front. Psychol. 2016, 7, 1182. [CrossRef] [PubMed]

39. Di Fabio, A. Green positive guidance and life counseling: New perspectives and first contribution to the Italian validation of the Connectedness to Nature Scale. Couns. G. Ital. Ric. E Appl. 2016, 9. [CrossRef]

40. Dazzi, C. The Eysenck personality questionnaire-Revised (EPQ-R): A confirmation of the factorial structure in the Italian context. Personal. Individ. Differ. 2011, 50, 790-794. [CrossRef]

41. Eysenck, S.B.G.; Eysenck, H.J.; Barrett, P. A revised version of the psychoticism scale. Personal. Individ. Differ. 1985, 6, 21-29. [CrossRef]

42. Hayes, A.F. Introduction to Mediation, Moderation, and Conditional Process Analysis: A Regression-Based Approach; Guilford Press: New York, NY, USA, 2013.

43. Hayes, A.F. PROCESS: A Versatile Computational Tool for Observed Variable Mediation, Moderation, and Conditional Process Modeling. White Paper. 2012. Available online: https://pdfs.semanticscholar.org/e9bb/ 7b23993113a73ee1ff6cde5ff9a4164f946e.pdf (accessed on 4 July 2019).

44. Cohen, J. Statistical Power Analysis for the Behavioral Sciences, Rev. ed.; Academic Press: New York, NY, USA, 1977; ISBN 978-0-12-179060-8.

45. Preacher, K.J.; Kelley, K. Effect size measures for mediation models: Quantitative strategies for communicating indirect effects. Psychol. Methods 2011, 16, 93-115. [CrossRef] [PubMed]

46. Eysenck, H.J. A Model for Personality; Springer Science \& Business Media: New York, NY, USA, 2012; ISBN 978-3-642-67783-0.

47. Eysenck, H.J.; Eysenck, S.B.G. Psychoticism as a Dimension of Personality; Hodder \& Stoughton: London, UK, 1976.

48. Eysenck, H.J. Personality: Biological foundations. In The Neuropsychology of Individual Differences; Academic Press: San Diego, CA, USA, 1994; pp. 151-207, ISBN 978-0-12-718670-2.

49. Eysenck, H.J.; Prell, D.B. The Inheritance of Neuroticism: An Experimental Study. J. Ment. Sci. 1951, 97, 441-465. [CrossRef] [PubMed]

50. Malaguti, E. Educarsi Alla Resilienza: Come Affrontare Crisi e Difficoltà e Migliorarsi; Edizioni Erickson: Trento, Italy, 2005; ISBN 978-88-7946-812-1.

51. Di Fabio, A.; Van Esbroeck, R. Intrapreneurial Self-Capital: A concept fitting a life-designing intervention. Couns. G. Ital. Ric. E Appl. 2016, 9. [CrossRef]

52. McIlveen, P.; Di Fabio, A. Intrapreneurial Self-Capital Training: A Case Study of an Italian University Student. In Narrative Interventions in Post-Modern Guidance and Career Counseling: A Review of Case Studies and Innovative Qualitative Approaches; Di Fabio, A., Bernaud, J.-L., Eds.; Springer International Publishing: Cham, Switzerland, 2018; pp. 197-209, ISBN 978-3-319-98300-4.

53. Arnoux-Nicolas, C.; Sovet, L.; Lhotellier, L.; Di Fabio, A.; Bernaud, J.-L. Perceived Work Conditions and Turnover Intentions: The Mediating Role of Meaning of Work. Front. Psychol. 2016, 7. [CrossRef]

54. Segura-Camacho, A.; García-Orozco, J.-J.; Topa, G. Sustainable and Healthy Organizations Promote Employee Well-Being: The Moderating Role of Selection, Optimization, and Compensation Strategies. Sustainability 2018, 10, 3411. [CrossRef]

55. Cole, L.B.; Altenburger, E. Framing the Teaching Green Building: Environmental education through multiple channels in the school environment. Environ. Educ. Res. 2017,1-20. [CrossRef]

56. Bee Seok, C.; Abd Hamid, H.S.; Ismail, R. Psychometric Properties of the Intrapreneurial Self-Capital Scale in Malaysian University Students. Sustainability 2019, 11, 881. [CrossRef]

57. Di Fabio, A.; Peiró, J.M. Human Capital Sustainability Leadership to Promote Sustainable Development and Healthy Organizations: A New Scale. Sustainability 2018, 10, 2413. [CrossRef]

58. Di Fabio, A.; Tsuda, A. The Psychology of Harmony and Harmonization: Advancing the Perspectives for the Psychology of Sustainability and Sustainable Development. Sustainability 2018, 10, 4726. [CrossRef]

59. Duradoni, M.; Paolucci, M.; Bagnoli, F.; Guazzini, A. Fairness and Trust in Virtual Environments: The Effects of Reputation. Future Internet 2018, 10, 50. [CrossRef]

60. Collodi, S.; Panerati, S.; Imbimbo, E.; Stefanelli, F.; Duradoni, M.; Guazzini, A. Personality and Reputation: A Complex Relationship in Virtual Environments. Future Internet 2018, 10, 120. [CrossRef] 
61. Guazzini, A.; Duradoni, M.; Lazzeri, A.; Gronchi, G. Simulating the Cost of Cooperation: A Recipe for Collaborative Problem-Solving. Future Internet 2018, 10, 55. [CrossRef]

62. Tetrick, L.E.; Peiró, J.M. Occupational Safety and Health. Oxf. Handb. Organ. Psychol. 2012, 2. [CrossRef]

63. Ceptureanu, S.I.; Ceptureanu, E.G.; Olaru, M.; Vlad, L.B. An Exploratory Study on Coopetitive Behavior in Oil and Gas Distribution. Energies 2018, 11, 1234. [CrossRef] 